\title{
Neologismo em Paresi-Haliti
}

Neologism in Paresi-Haliti

\author{
Izaira de Oliveira Costa \\ Universidade Federal do Pará (UFPA) \\ Ana Paula Barros Brandão \\ Universidade Federal do Pará (UFPA)
}

\begin{abstract}
Resumo. O artigo apresenta uma descrição e análise do processo de formação de neologismos na língua Paresi-Haliti através de pesquisa bibliográfica, utilizando-se os trabalhos de Rowan (2001); Silva (2013); Brandão (2014) e Brandão (2016). Na língua Paresi ainda não há trabalhos que tenham como foco o fenômeno neológico. Com base em Alves (1999), Manzollilo (2001) e Carvalho (1989), analisamos os neologismos em Paresi considerados como palavras novas que resultam da necessidade de nomear termos vindos do português. Na língua Paresi, o neologismo formal destaca-se como o mais produtivo e é formado pelos seguintes processos: derivação com classificadores (como em txinitse 'gato', txini 'onça' e -tse 'classificador para pequeno') e com o nominalizador instrumental -kala (a exemplo da palavra iraikalati 'telefone', irai 'falar' e -kala 'nominalizador de instrumento'); e composição com dois nomes (como em zotsemili 'lente de contato', zotse 'olho' e mili 'pele'). Este trabalho visa contribuir com a valorização, fortalecimento e revitalização da língua Paresi-Haliti.
\end{abstract}

Palavras-chave: Mudança linguística; Neologismo; Paresi-Haliti.

Resumo. The article presents a description and analysis of the neologism formation process in the ParesiHaliti language through bibliographic research, using the works of Rowan (2001); Silva (2013); Brandão (2014) and Brandão (2016). In the Paresi language there are still no works that focus on the neological phenomenon. Based on Alves (1999), Manzollilo (2001) and Carvalho (1989), we analyzed neologisms in Paresi considered as new words that result from the need to name terms from Portuguese. In Paresi, formal neologism stands out as the most productive, and it is formed by the following processes: derivation with classifiers (as in txinitse 'gato', txini 'jaguar' and -tse 'classifier for small') and with the instrumental nominalizer -kala (for example, the word iraikalati 'telephone', irai 'speak' and -kala 'instrument nominalizer'); and composition with two names (as in zotsemili 'contact lens', zotse 'eye' and mili 'skin'). This work aims to contribute to the enhancement, strengthening and revitalization of the Paresi-Haliti language.

Palavras-chave: Linguistic change. Neologism. Paresi-Haliti.

\section{Introdução}

No Brasil, as pesquisas científicas que se desenvolvem em torno das línguas indígenas apontam que, desde a chegada do europeu, há um grande decréscimo das línguas e populações indígenas. 0 contato entre a língua Portuguesa, que desde o início se impôs como língua majoritária, e as línguas indígenas, resultou em sobreposição de uma cultura sobre a outra. Este trabalho apresenta a situação de contato entre a língua Paresi-Haliti (chamada apenas de Paresi daqui em diante), da família Aruák, e o português. Nossa pesquisa teve como objetivo geral descrever e analisar os processos de formação dos neologismos em Paresi e contribuir com a pesquisa neológica, destacando a importância do seu papel para a preservação da cultura e língua indígena. De acordo 
com Brandão (2014), 90\% dos falantes têm a língua Paresi como língua materna. Contudo, uma ameaça a essa língua é o empréstimo de algumas palavras vindas da língua Portuguesa. Nesse sentido, Brandão (2014) destaca que a incorporação de tais palavras pode resultar em mudanças significativas para a língua Paresi.

Tendo em vista o processo de vitalidade das línguas indígenas e preservação cultural de tais comunidades, a relevância deste trabalho se mostra na descrição científica da língua Paresi e em contribuir com a pesquisa neológica, visando assim servir de base para o próprio conhecimento indígena e incentivar a preservação cultural através da língua. Com base na criação do fenômeno neológico procuramos responder as seguintes perguntas: Como ocorre o processo de criação neológica? Qual processo é mais fecundo na língua? Qual a importância do neologismo para a língua Paresi?

Nossa pesquisa é de caráter bibliográfico e segue uma abordagem qualitativa, em que foram selecionados e analisados um número total de (72) neologismos encontrados no corpus da língua Paresi. Para isso, tivemos como fonte para a seleção de dados os trabalhos de Brandão (2014) e o acervo de Brandão (2014) organizado no programa FLEx (Fieldworks Language Explorer); o trabalho de Silva (2013) e o Dicionário Português-Paresi de Rowan (2001). O trabalho de Brandão (2014) resulta de pesquisa de campo entre os anos de 2006 e 2012.

Este trabalho está dividido em quatro partes. Na seção 2, apresentamos informações gerais sobre os Paresi, o território, as transformações históricas que ocorreram através do contato com o não-indígena e a organização social. Em seguida, mencionamos a relação entre língua e falante, e apresentamos alguns de seus aspectos estruturais. A seção 3 apresenta as principais referências sobre neologismos. Na seção 4, descrevemos a criação de neologismos em Paresi e em seguida a análise das criações neológicas. A última seção apresenta as considerações finais sobre o trabalho, destacando as principais contribuições.

\section{O povo e a língua Paresi}

Os Paresi estão localizados no estado de Mato Grosso, próximo à cidade de Cuiabá, nos tributários do rio Juruena, na savana. Com uma população de aproximadamente 3.000 pessoas, estão distribuídos em nove terras indígenas: Rio Formoso, Utiariti, Estação Parecis, Estivadinho, Pareci, Juininha, Figueira, Ponte de Pedra e Uirapuru. (BRANDÃO, 2014). Os Paresi se autodenominam Paresi-Haliti, cujo significado pode ser traduzido como "gente", "povo. Os Paresi estão divididos em subgrupos: Kozárini, Kaxiniti, Warere, Kawali, Wámare. De acordo com Costa (1985) atualmente existem apenas três subgrupos, os Kozárini, Kaxiniti e Wáimare.

Segundo Canova (2003), os primeiros escritos que mencionam a etnia Paresi os descrevem como gentios, mais predispostos a inclusão dos "valores" impostos pelos não-indígenas, ao contrário de outras nações que eram consideradas bárbaras, infiéis e impossíveis de serem catolizadas. Assim, ao longo dos séculos os Paresi foram alvo de diversas frentes de intervenções sociais que resultaram na adoção de valores e padrões sociais. Dentre os que podemos citar estão as atividades econômicas que não existiam antes do contato dos índios Paresi com o homem branco, tais como o plantio de soja e a criação de animais como porcos, patos, bois, galinhas, cavalos etc. $O$ uso do arco-flecha nas atividades tradicionais como a caça foi aos poucos sendo substituído pela 
caça com armas de fogo. Por fim, entende-se que as intervenções que ocorreram ao longo dos séculos interferiram diretamente na cultura sendo observado no modo de viver desse povo.

A língua Paresi é uma das cerca de 40 línguas da família Aruák (BRANDÃO, 2014). Tal língua é classificada por Aikhenvald (1999) como Aruák do Sul, formando o ramo Paresi-Xingu. De acordo com Brandão (2014), 90\% dos Paresi são falantes da língua, tendo o Português como segunda língua. A esse respeito a autora destaca que, apesar do Paresi constituir a língua materna desse povo e ser usada na socialização, isto é, ser usada no dia a dia pelos falantes, tal língua corre risco de extinção, uma vez que o bilinguismo se faz presente nessas comunidades, sendo cada vez mais comum o uso da língua Portuguesa (seja por meio dos empréstimos que se inserem na língua, ou devido a necessidade do uso do Português nas atividades que se realizam fora da aldeia).

No que se refere ao caráter estrutural da língua, Brandão (2014) destaca que a língua possui quatorze consoantes e quatro vogais, acento não contrastivo e estrutura silábica (C) V (V). É polissintética, de núcleo marcado e aglutinativa como as outras línguas da família Aruák. Sua morfologia consiste de vários morfemas com fronteiras bem delimitadas (sem morfemas cumulativos) e alguma variação alomórfica. As classes de palavras estão divididas em abertas (nomes e verbos) e fechadas (adjetivos, advérbios, pronomes demonstrativos, indefinidos, numerais, quantificadores, posposições, interjeições e ideofones).

Silva (2009) e Brandão (2014) descrevem uma variedade da língua Paresi, chamada de variante majoritária; variedade também analisada nesta pesquisa. Conforme os autores, a variação está relacionada aos grupos sociais, isto é, a variedade majoritária é relacionada aos grupos Kozarene e a minoritária ao o grupo Waimaré.

\section{Neologismos}

As mudanças que ocorrem no léxico de uma língua estão relacionadas às transformações históricas e políticas que se realizam em uma determinada sociedade. Assim, uma forma de entender a cultura de um povo é conhecer sua língua, uma vez que as línguas estão em constante mudança e renovamse a cada momento. Biderman (2001) atribui ao léxico, parte visível da língua, principal meio de se conhecer a cultura de um povo:

[...] a janela através da qual uma comunidade pode ver o mundo, uma vez que esse nível da língua é o que mais se deixa transparecer os valores, as crenças, os hábitos e costumes de uma comunidade, como também as inovações tecnológicas, transformações sócioeconômicas e políticas ocorridas numa sociedade. Em vista disso o léxico de uma língua conserva uma estrita relação com a história cultural da comunidade. (BIDERMAN, 2001. p. 9).

Nesse sentido, entende-se que a língua está em constante mudança, pois toda língua possui o seu mecanismo de criação e revitalização linguística. É através do léxico que novas palavras surgem a todo o momento, sejam palavras que surgem do contato com outras línguas, ou palavras que fazem parte da cultura do falante, que a todo momento está criando ou ressignificando novos termos. As mudanças de caráter sociocultural consequentemente implicam na criação de novos vocábulos para atender os anseios do falante. Assim, novos termos são criados, uns desaparecem, alguns adquirem outros sentidos e ainda outros são incorporados de outros idiomas. Esse fenômeno recebe o nome de neologismo. Manzollilo (2001), por sua vez, o define como um mecanismo de 
inovação lexical: "[...] uma palavra nova, forjada com o escopo de responder linguisticamente a uma necessidade surgida no contexto biossocial, algo que circula entre o caráter ilimitado da realidade a ser expressa e as limitações do sistema linguístico" (MANZOLLILO, 2001. p.12).

O contato entre culturas é um dos principais fatores responsáveis pelas mudanças que ocorrem nas línguas, seja a nível estrutural ou lexical. Essas mudanças são ocasionadas pela influência que uma língua majoritária exerce sobre uma minoritária. De uma forma geral, a língua Portuguesa vem exercendo uma grande influência sobre o léxico das línguas indígenas. Isso porque surgem novas palavras para designar, por exemplo, objetos (sapato, óculos, celular, televisão etc.), como também, itens lexicais que fazem referência a profissões, a atividades econômicas, processos de compra e venda etc., que até então não faziam parte do domínio vocabular desses povos.

Essas palavras são incorporadas na língua por meio de dois mecanismos de ampliação lexical, os que utilizam a própria língua para criar novas palavras, os neologismos (como por exemplo, a palavra para 'café' em Waurá: yalakiya em que, yala significa preto, ou água preta) e os que incorporam palavras de outros sistemas linguísticos, os empréstimos. Com relação ao segundo, destaca-se que em algumas línguas indígenas, tais como Guarani Kaiowá, Wapichana e Munduruku, o empréstimo linguístico tem sido usado com maior frequência, o que se torna preocupante, posto que em algumas comunidades a aceitação dos termos da língua Portuguesa ocorre de forma passiva. Na maioria das vezes essas incorporações são feitas sem sofrer nenhum tipo de modificação na língua receptora, e nos poucos casos em que há essa alteração, modifica-se um fonema por outro equivalente, como descrito nos exemplos de palavras referentes a 'café' nessas línguas: kapedi (em Munduruku) e kafe (em Yawalapiti) (OLIVEIRA et al, 2014, p. 314). Calvet (2002) aponta o bilinguismo como motivação para incidência de empréstimo nas línguas: "a interferência lexical pode produzir o empréstimo: mais que procurar na própria língua um equivalente a um termo de outra língua difícil de encontrar, utiliza-se diretamente essa palavra adaptando-a à própria pronúncia." (CALVET, 2002. p. 31).

Portanto, a adoção do empréstimo nas línguas indígenas é mais comum e prática do que o processo neológico, ou seja, "a cunhagem de um novo termo demanda tempo e interesse, enquanto que a adoção é instantânea". (CARVALHO, 1989. p. 80). Porém, como forma de preservar a língua, alguns povos como os Bakairi e os Tapirapé adotaram os neologismos como uma maneira de frear um número significante de empréstimo que estavam sendo incorporados à língua. Veremos na seção 4, que esse é o caso da língua Paresi.

Biderman (1978) afirma o empréstimo pode causar grandes consequências para a língua receptora, pois as palavras emprestadas resultam no abandono de algumas palavras que desempenham funções equivalentes, elas ainda ameaçam a integridade do sistema linguístico da língua receptora, isto é, o próprio processo de formação de palavras. (BIDERMAN, 1978.p. 161).

Conforme Carvalho (1989), há dois processos de ampliação lexical: os processos de criação dentro da própria língua", os neologismos e o "processo de adoção e adaptação da língua, o chamado empréstimo linguístico (CARVALHO, 1989. p. 24). Carvalho (1989) e Manzollilo (2001) não consideraram o empréstimo como um tipo de neologismo, já Biderman (1978), Barbosa (1978) e Alves (1984) consideram o empréstimo como um tipo de neologismo. Nesse trabalho a concepção adotada será a de Carvalho (1989). 
O fenômeno neológico subdivide-se em quatro tipos: fonológico, semântico, sintático e morfológico. Autores como Biderman (1978) e Carvalho (2006) apresentam uma outra classificação para neologismo sintático ou morfológico. Tais autores o denominam como neologismo formal, uma vez que a criação neológica une elementos morfológicos e sintáticos. Dessa forma, tais processos não podem ser descritos separadamente. Assim, entendemos que a nomenclatura "neologismo formal" é mais coerente na classificação de processos morfossintáticos. Sendo assim, adotamos a definição de Carvalho (2006): "o neologismo formal constitui uma palavra nova introduzida no idioma, podendo ser vernácula ou estrangeira." (CARVALHO, 2006. p. 195). Neste trabalho, será dado foco apenas para o neologismo formal, já que se mostrou mais fecundo na língua pesquisada.

Com relação ao neologismo sintático-morfológico, ou formal como mencionamos, segundo Alves (1999), constitui-se como o mais produtivo nas línguas, já que resulta da combinação de elementos já existentes no sistema. De acordo com a autora, esse tipo de neologismo consiste no processo de formação neológica criado através dos seguintes mecanismos: derivação, composição, formações por siglas e composição sintagmática.

\section{Neologismos em Paresi}

\subsection{Os Paresi e os neologismos}

Segundo Canova (2003), o contato do povo Paresi com o não-índio, ocorreu primeiro no século XVII com as missões sertanistas, e ao mesmo tempo com as missões religiosas; e se intensificou no final do século XIX, com a extração do látex da borracha continuando com a missão Rondon e o projeto de implantação das linhas telegráficas, o que culminou em grandes transformações econômicas e culturais para esse povo.

Antes do contato com o não-índio, os Paresi viviam da coleta, da pesca e da caça. Contudo, o convívio lado a lado com o não-indígena influenciou na forma de viver desse povo. Atualmente, uma das atividades econômicas que se desenvolve em território Paresi é a agricultura. $O$ turismo também é uma das principais atividades que movimentam a economia de algumas aldeias indígenas. A educação escolar também se faz presente nas comunidades indígenas. Em meio a essas transformações, a tecnologia se faz presente no dia-a-dia desse povo. Nessas comunidades, a tradição convive lado a lado com o "progresso" tecnológico. A exemplo de muitas famílias que vivem em hati 'moradia tradicional' dos Paresi, com pisos, móveis, aparelhos eletrônicos, telefones celulares, utensílios etc.

Com a incorporação desses novos objetos na cultura Paresi, também se incorporam as palavras que lhes denominam. Contudo, nossa pesquisa constatou que os Paresi não aceitam passivamente as palavras vindas de outras línguas, com isso criam, traduzem, nomeiam essas palavras estrangeiras utilizando palavras da própria língua.

Na língua Paresi ainda não há trabalhos que tenham como foco o fenômeno neológico. Nessa seção, descrevemos o neologismo em Paresi, como a criação de uma palavra nova que resulta da necessidade de nomear/traduzir termos vindos de outras línguas. Isso se explica pelo fato de alguns itens lexicais não fazerem parte da cultura dos falantes. Assim, eles emprestam, ou nomeiam esses 
itens. Os falantes utilizam a relação entre objeto/função e/ou característica/semelhança física para criar neologismos.

\subsection{Processos de formação de palavras}

No corpus da língua Paresi foram encontrados um total de 72 neologismos formados pelos processos de derivação com sufixos nominalizadores, derivação com classificadores e composição com dois nomes.

\subsubsection{Neologismos formados pelo processo de derivação}

A derivação sufixal é um processo de criação neológica bastante produtiva em Paresi. Isso reforça a hipótese de que as línguas em geral utilizam o processo de derivação para criar neologismos. Dentre o número total de 72 neologismos encontrados no corpus da língua, utilizado nesta pesquisa, 25 foram formados pelo processo de nominalização com o sufixo -kala, 7 com o sufixo -re e 15 foram formados pela derivação com classificadores.

\section{a) Nomes derivados com o sufixo -kala}

A criação de neologismos com o nominalizador instrumental -kala foi a mais produtiva na língua. Isso porque a partir do sufixo -kala criam-se nomes referentes a utensílios, objetos tecnológicos etc. Esses elementos vêm sendo inseridos na cultura indígena desde os primeiros contatos com o nãoindígenas. Já as criações com o sufixo -re, resulta em palavras referentes a profissões. Essas palavras só foram introduzidas na língua Paresi há pouco tempo.

Segundo Brandão (2014), no processo de derivação, o sufixo -kala se aplica a verbos intransitivos e transitivos para derivar nomes que fazem referência a instrumento ou local. Estes nomes derivados são nomes inalienáveis que recebem o sufixo -ti quando não possuídos e os clíticos pessoais quando possuídos.

Na língua Paresi, a criação de neologismos ocorre quando o sufixo -kala ocorre com uma raiz verbal intransitiva, como no exemplo (1), ou transitiva (2). A derivação sufixal altera a classe gramatical da palavra e resulta em um nome referente a instrumento ou localização.

(1) kakoahakalati

kakoaha -kala-ti

subir-NMLZ-N.POSS

escada 'objeto usado para subir' (BRANDÃO, 2014).

(2) zairatyakalati

zaira-tya-kala-ti

escrever-TH-NMLZ-N.POSS

'caneta, lápis, 'objeto usado para escrever' (BRANDÃO, 2014)

Os processos de nominalização em que o sufixo -kala deriva nomes de verbos intransitivos não são produtivos na língua. Foram encontrados apenas três exemplos desse processo no corpus 
da língua. Em Paresi foram encontrados mais casos de derivação instrumental com o verbo transitivo, como mostra o quadro abaixo:

Quadro 1: Derivação com o nominalizador instrumental -kala:

\begin{tabular}{|c|c|c|c|c|}
\hline & Verbo & Glosa & Nome derivado & Glosa \\
\hline 1. & Irai & Falar & $\begin{array}{c}\text { iraityakalati } \\
\text { irai-tya-kala-ti } \\
\text { falar-TH-NMLZ-NPOSS }\end{array}$ & $\begin{array}{c}\text { telefone celular } \\
\text { 'objeto usado para falar' }\end{array}$ \\
\hline 2. & axika & mandar & $\begin{array}{c}\text { zaxikazatyakalati } \\
\text { z-axika-za-tya-kala-ti } \\
\text { NMLZ-mandar-CLF-TH-NMLZ-NPOSS }\end{array}$ & $\begin{array}{c}\text { Telefone } \\
\text { 'objeto usado para mandar } \\
\text { mensagem' }\end{array}$ \\
\hline 3. & tsema & escutar & $\begin{array}{c}\text { tsemakatykalati } \\
\text { tsema-ka-tya-kala-ti } \\
\text { escutar-CAUS-TH-NMLZ-NPOSS }\end{array}$ & $\begin{array}{l}\text { telefone 'objeto usado para } \\
\text { escutar, receber mensagem' }\end{array}$ \\
\hline 4. & tiha & Lavar & $\begin{array}{c}\text { tihakalati } \\
\text { tiha-kala-ti } \\
\text { lavar-NMLZ-NPOSS }\end{array}$ & $\begin{array}{c}\text { sabão } \\
\text { 'algo usado apara lavar' }\end{array}$ \\
\hline 5. & tiha & Lavar & $\begin{array}{c}\text { tiha-kala-ti } \\
\text { lavar- NMLZ-NPOSS }\end{array}$ & $\begin{array}{c}\text { máquina de lavar } \\
\text { 'objeto usado para lavar' }\end{array}$ \\
\hline 6. & aokanatya & brilhar & $\begin{array}{c}\text { ezoaokanatyakala } \\
\text { e-z-aokanatya-kala } \\
\text { 3SG-NMLZ-brilhar-NMLZ }\end{array}$ & $\begin{array}{c}\text { lamparina } \\
\text { 'objeto usado para iluminar' }\end{array}$ \\
\hline 7. & aokanatya & brilhar & $\begin{array}{c}\text { ezoaokanatyakala } \\
\text { e-z-aokanatya-kala } \\
\text { 3SG-NMLZ-brilhar-NMLZ }\end{array}$ & $\begin{array}{c}\text { vela } \\
\text { 'objeto usado para iluminar' }\end{array}$ \\
\hline 8. & ehokotya & Deitar & $\begin{array}{c}\text { ezehokotyakalati } \\
\text { e-z-ehokotya-kala-ti } \\
\text { 3SG-NMLZ-deitar- NMLZ-NPOSS }\end{array}$ & $\begin{array}{c}\text { Cama } \\
\text { ‘objeto usado para deitar' }\end{array}$ \\
\hline
\end{tabular}

Alguns exemplos são casos complexos, como os itens 1, 2 e 3 do quadro 1, nos quais foram encontrados mais de um termo para o mesmo referente. O referente 'telefone' é traduzido pelos Paresi como instrumento usado para falar, receber e enviar mensagem. Há duas hipóteses para explicar esse fato: consideramos que os dados podem ter sido criados por falantes diferentes de uma mesma comunidade ou que possam ser termos usados em diferentes comunidades (variação diatópica); hipóteses que ainda precisam ser investigadas.

Já nos itens 4 e 5 ocorreu o contrário, isto é, há apenas um referente para objetos distintos. Nesse caso, sabemos que foram falantes de diferentes comunidades que nomearam sabão e máquina de lavar com a palavra tihakalati. Isso se explica pelo fato de que, para criar neologismo, os falantes utilizam a relação entre objeto/função e/ou característica/semelhança física. Assim, ao nomear os objetos máquina de lavar e sabão, os falantes levaram em consideração a utilidade, finalidade que esses objetos apresentam, ou seja, a de lavar. Também observamos que nesses exemplos temos um caso de polissemia, ou seja, a palavra tihakalati apresenta mais de um significado.

$\mathrm{Na}$ derivação com o sufixo -kala também encontramos casos de extensão metafórica, a exemplo dos itens 6 e 7, em que, além de apresentarem o mesmo termo para objetos distintos, mostram uma generalização, uma extensão metafórica da palavra original. Nesse caso, a nomeação não teve como princípio apenas a função/característica do objeto, mas a extensão metafórica, pois 
o significado do verbo brilhar foi estendido para aquilo que tem luz, que ilumina. Dessa forma, há uma generalização do verbo 'aotya', que passa a significar não só 'vela' e 'lamparina', mas tudo aquilo que ilumina ou que é usado para iluminar. Esses foram os únicos exemplos de extensão metafórica ocorrendo com o sufixo -kala, contudo, serão descritos vários exemplos de extensão metafórica, principalmente na derivação com classificadores descrita a seguir.

Dando continuidade, encontramos na língua Paresi, outras duas palavras para o mesmo referente, porém uma é neologismo e a outra é um empréstimo linguístico da língua portuguesa:

(3) ezehokotyakalati

e-z-ehokotya-kala-ti

3SG-NMLZ-deitar-NMLZ-N.POSS

cama 'objeto usado para deitar' (BRANDÃO, 2014)

(4) kama

'cama' (BRANDÃO, 2014)

Para diferenciar neologismo de empréstimo linguístico, utilizamos como critério os processos de formação desses termos, ou seja, o neologismo é criado pelo processo de derivação, composição etc., utilizando termos da língua para traduzir termos de culturas externas, como podemos observar no exemplo (3); já no caso do empréstimo ocorre apenas a adaptação fonológica da palavra emprestada a língua receptora em alguns casos (o que não ocorre em (4)). Nesses exemplos não foi possível identificar se são falantes diferentes, ou informar se tais palavras ocorreram em contextos diferentes, pois não encontramos essas palavras em textos, mas no banco de dados lexical.

Com base nos dois exemplos, constatou-se que os Paresi têm a língua como um forte fator de preservação da cultura e identidade. Assim, a maioria dos utensílios que são introduzidos na língua, os Paresi nomeiam/traduzem utilizando mecanismos da própria língua.

\section{b) Nomes derivados com o sufixo -re}

O sufixo -re deriva nomes a partir de verbos transitivos, intransitivos e de adjetivos. Os nomes derivados fazem referência ao agente do evento expresso pelo verbo. (BRANDÃO, 2014). Os neologismos resultantes da nominalização com o -re denotam nomes de profissões ou àqueles que desempenha uma função, como em (5) e (6). No dado (5), nota-se que polícia é aquela que tem a função de amarrar/prender. Já no dado (6), observa-se que o médico é aquele que desempenha a função de curar.

(5) olatya-re ola-tya-re amarrar-TH-NMLZ

Polícia 'aquela que amarra' (SILVA, 2013)

(6) wairatyare

waira-tya-re

curar-TH-NMLZ

Médico 'aquele que cura' (BRANDÃO, 2014) 
Os nomes derivados pelo sufixo -re podem ser possuídos pelos clíticos pessoais e pelas formas -tse para o masculino e -tsero para o feminino. Abaixo há alguns exemplos de nomes possuídos com a forma -tse e exemplos de nomes possuídos com -tsero.

(7) ezawaiyetyatse

e-z-awaiyetya-tse

3SG-NMLZ-gostar de-POSS

amigo 'quem gosta de nós' (BRANDÃO, 2014)

(8) ezaotyakitsatse

e-z-aotyakitsa-tse

3 SG-NMLZ-ensinar-POSS

Professor 'aquele que ensina' (BRANDÃO, 2014)

(9) wairatyatsero

e-waira-tya-tsero

3 SG -curar-TH-POSS

Enfermeira 'aquela que cura' (BRANDÃO, 2014)

Cabe destacar que, no caso de zawaiyetyatse 'amigo', entende-se que a palavra não faz referência à profissão, porém apresenta uma relação de "desempenha uma função".

\section{c) Derivação com classificadores}

A derivação com classificadores, se comparada a derivação com o sufixo -kala, não é produtiva na língua, todavia, os classificadores apresentaram um número significativo de neologismos referentes a utensílios e animais. De acordo com Brandão (2014), na língua Paresi, os classificadores são morfemas presos que desempenham função derivacional. Podem derivar nomes de nomes e nomes de verbos. No processo de derivação com classificadores considerados neologismos, só foram encontrados neologismos derivados de nomes. Todos os neologismos criados pelo processo de derivação com classificadores, tiveram seus significados estendidos, ou passaram pelo processo de associação metafórica.

Dentre os classificadores que participam da criação de neologismos, destacam-se a forma tse, classificador para pequeno; -hi, classificador para longo, -natse, que se refere a elementos cilíndricos, ou animais quadrúpedes, e/ou horizontalmente longos (ROWAN, 2001, p. 15); -he e ho fazem referência a pó e a forma -za que é usada para fazer referência a líquido, e também tem uma forma homônima que corresponde a fala. Em nossa pesquisa encontramos apenas 15 casos de neologismos criados pela derivação com os classificadores. Com o classificador -hi encontramos mais casos, no total de 5 neologismos, com a forma -he, e tse encontramos três casos com cada um, com o classificador -natse encontramos 2 exemplos, já com os classificadores -za $e$-ho foram encontrados apenas 1 exemplo, com cada um deles. 
O classificador - hi originou-se de nomes de raízes presas de partes de plantas, como 'fibra $\mathrm{de}^{1}{ }^{1}$ no entanto, passou a referir-se a entidades que lembram o formato de cipó, como mostra os exemplos abaixo:

(10) olawahi olawa-hi tucum-CLF 'corda' (BRANDÃO, 2014)

Nesse exemplo, temos o nome 'olawa', que significa 'tucum', uma palmeira da qual se utilizam as folhas para extrair as fibras que se assemelham a fios, e o classificador - $h i$, que denota elementos com o formato de cipó, ou alongado. Na comunidade Paresi, a fibra de tucum era usada para fazer cordas, com o tempo, o termo olawa 'tucum' juntou ao classificador 'hi' passou a referirse a qualquer tipo de corda. Outro exemplo encontrado na língua com o classificador -hi foi o termo itimazahi 'energia', mostrado no exemplo abaixo:

(11) nitimazahi

n-itima-za-hi

3SG-fogo-POSS-CLF

'energia' (BRANDÃO, 2014)

Por meio desse exemplo, nota-se que o falante utilizou o processo de associação metafórica para criar a unidade 'itimazahi' (energia), em que fogo se assemelha à luz, e os fios fazem referência aos fios de energia, ou seja, para o falante, energia seria 'fogo que é levado através de fios'. Na língua Paresi, também foram encontrados exemplos, em que o classificador - $h i$ foi lexicalizado, como ilustrado abaixo:

(12) awiyahi awiyahi

'agulha' (BRANDÃO, 2014)

No exemplo exposto, observa-se que, o classificador - $h$ i refere-se ao formato comprido da agulha, ocorrendo lexicalizado, ou seja, não há como segmentar a palavra e apreender o significado de cada morfema, mas apenas entender o significado como um todo. Assim, infere-se que, em algum momento da língua, a raiz awiya pode ter ocorrido separada do classificador.

Em Paresi, encontramos ocorrências de formação neológica com o classificador -za, como exemplificado em (13). Podemos observar em (13) que a palavra itimaza 'gasolina', foi criada a partir da associação metafórica entre fogo e seu estado líquido, uma vez que a gasolina é uma substância inflamável, em estado líquido. Dessa forma, 'itimaza' significa fogo líquido.

(13) itimaza

itima-za

fogo-CLF

gasolina 'fogo líquido' (BRANDÃO, 2014)

\footnotetext{
${ }^{1}$ Os nomes referentes a partes de plantas são nomes inalienáveis, ou seja, inerentemente possuídos, por isso, tais nomes são acompanhados de "de" em português.
} 
Exemplo com o classificador '-he' também foi encontrado na língua como ilustra o dado abaixo:

(14) korehe

kore-he

flecha-CLF

pólvora 'pó da arma' (BRANDÃO, 2014)

Nos exemplos anteriores verificou-se que as palavras foram criadas a partir do processo de associação metafórica, contudo em (14), ocorreu associação e extensão metafórica ao mesmo tempo. Na língua Paresi a unidade 'kore' significa flecha, porém seu significado foi ampliado para arma, ou aquilo que está relacionado à arma. Nesse sentido, a raiz 'kore' junto ao classificador para pó '-he' significa pó da arma. Outros exemplos que têm como radical o nome 'kore' foram encontrados na língua Paresi, como exemplificado abaixo:

(15) korenatse

kore-natse

flecha-CLF

'espingarda' (BRANDÃO, 2014)

Na construção acima, nota-se que o classificador '-natse' é usado para fazer referência ao formato da arma, isto é, que apresenta um formato cilíndrico. Além de derivar nomes inanimados, o classificador -natse também ocorre lexicalizado como demonstrado no exemplo abaixo:

(16) halanatse

halanatse

'cachorro' (BRANDÃO, 2014)

De acordo com Rowan (2001), -natse representa uma classe de animais, animais quadrúpedes (como veado, lobo); nesse sentido, entende-se que a criação neológica resulta, possivelmente da relação de semelhança entre esses animais e o cachorro.

Em nossa análise, o critério que utilizamos para saber se uma palavra criada é um neologismo, é o fato de o termo criado fazer referência a um objeto, ação etc., que pertence a cultura Paresi, ou pertencia a uma cultura externa, e posteriormente foi introduzida na língua. Como, por exemplo, a palavra halanatse 'cachorro', que foi inserida na cultura Paresi por meio do contato com o não-indígena, pois 'cachorro' não fazia parte da cultura desse povo, já que o povo não tinha o hábito de domesticar animais. Assim, criou-se o termo halanatse para nomear a referente vindo de outra cultura. Também é importante ressaltar que o termo 'halanatse' tem como concorrente a palavra 'katxolo', palavra emprestada da língua Portuguesa. Isso significa que os Paresi não apenas aceitam passivamente os termos advindos de outras línguas, mas que também utilizam o processo neológico para traduzir termos estrangeiros. Na língua Paresi o neologismo se configura como um mecanismo de revitalização e ao mesmo tempo manutenção da língua e uma prova disso é o grande número de neologismos criados pelos falantes.

Dando continuidade à categoria animal, destaca-se o classificador -tse, que deriva termos referentes a animais, como ilustrado abaixo: 
(17) txinitse

txini-tse

onça-CLF

gato 'pequena onça' (BRANDÃO, 2014)

O classificador '-tse' é usado para denotar nomes de coisas pequenas, porém, nesse caso tse não é usado para fazer referência a onça filhote, mas para se referir a um animal de pequeno porte que apresenta características físicas com a onça, e que assim como a onça também é um felino.

\subsubsection{Neologismos criados pelo processo de composição}

Na língua Paresi, a criação de neologismos que ocorre através do processo de composição não é produtiva. Em nossa pesquisa, coletamos apenas dois termos neológicos criados por esse processo, ilustrados em (18) e (19).

(18) zotsemili

zotse -mili

olho-pele

pele do olho 'lente de contato' (BRANDÃO, 2014)

(19) zotsemeritane

zotse-miri-tane

olho-picar-pena

'cílios' (BRANDÃO, 2014)

Os compostos nominais em Paresi são classificados em exocêntrico e endocêntrico (PEREIRA, 2017). De acordo com os dados acima, classificamos os compostos neológicos como endocêntricos, pois o significado do composto não pode ser apreendido a partir do significado de suas partes, mas a partir de fatores culturais e pragmáticos que resultam na nomeação metafórica. Em (18), o termo zotsemili 'lente de contato' resulta de uma associação metafórica em que mili 'pele' é associado ao aspecto fino da lente de contato. No exemplo (19), o termo zotsemeritane 'cílios' também resulta de uma associação metafórica, entre tane 'pena' e cílios.

\section{Considerações finais}

Diante dos dados analisados procuramos descrever como ocorre o processo de criação de neologismos na língua Paresi. Nossa análise confirmou que os neologismos em Paresi são formados pelo processo de derivação e composição (com algumas exceções), observando que a derivação com o sufixo-kala se mostrou a mais produtiva.

Com um número total de 72 neologismos encontrados no corpus da língua Paresi, verificamos que criação de palavras para referentes vindos de outras culturas é uma prática comum entre os Paresi. Isso se explica por dois motivos, primeiro, pelo domínio que os falantes têm sobre a língua e segundo, pela forte relação identitária entre língua e falante.

Em Paresi, quem cria neologismo não é apenas pessoas escolarizadas, mas o falante em geral. Isso demostra que os Paresi têm uma grande percepção sobre a importância da língua para a 
preservação cultural e que têm um amplo domínio sobre a língua e consequentemente sobre o processo de criação de novas palavras. Porém, o número de neologismos coletados não demostra se o falante tem mais preferência pelo neologismo do que pelo empréstimo linguístico, já que em outro trabalho de Sousa (2018), apontou-se um número de 63 empréstimos. Esses empréstimos são usados no dia a dia e dificilmente são encontrados em textos tradicionais.

O que foi possível verificar é que alguns falantes, tais como idosos e professores, preferem usar palavras da própria língua, enquanto outros preferem usar os empréstimos. Acreditamos que a percepção de que as palavras vindas de outas línguas constituem uma ameaça para a língua, a cultura e a identidade desse povo, faz com que os neologismos sejam usados como um mecanismo de preservação e ao mesmo tempo revitalização da língua.

\section{Referências}

AIKHENVALD, A. Y. The Arawak language family. In: DIXON, R. M. W.; AIKHENVALD, A. Y. (Ed.). The Amazonian languages. Cambridge: Cambridge University, 1999. p. 65-106.

ALVES, I. M. Neologismo: Criação Lexical. 3 ed. São Paulo: Ática, 1999.

ALVES, I. M. A integração dos neologismos por empréstimo ao léxico português. Alfa: Revista de Linguística, v.28, 1984.

BARBOSA, M. A. Aspectos da dinamicidade dos neologismos. Literatura, n. 7, p. 185-208, 1978.

BIDERMAN, M. T. C. As ciências do léxico. In: OLIVEIRA, A. M.; ISQUERDO, A. (Orgs.). As ciências do léxico: lexicologia, lexicografia e terminologia. Campo Grande: Editora UFMS, 2001.

BIDERMAN, M. T. C. Teoria Linguística: linguística quantitativa computacional. Rio de Janeiro: LTC, 1978.

BRANDÃO, A. P. A reference grammar of Paresi-Haliti (Arawak). 2014. Tese (Doutorado em Linguística), Universidade do Texas, 2014.

BRANDÃO, A. P. A incorporação de nomes em Paresi-Haliti (Aruák). Liames, v. 16, n. 12, p. 271-283, jan./dez., 2016.

CALVET, L. J. Sociolinguística: uma introdução crítica. São Paulo: Parábola, 2002.

CANOVA, L. Os doces bárbaros: imagens dos índios Paresi no contexto da conquista portuguesa em Mato Grosso (1719-1757). 2003. Dissertação (Mestrado em História) - Universidade Federal do Mato Grosso, Cuiabá, 2003.

CARVALHO, N. M. Empréstimos linguísticos. São Paulo: Ática, 1989.

CARVALHO, N. M. A criação neológica. Revista Trama, vol. 2, n. 4, p. 191-203, 2006.

COSTA, R. M. R. Cultura e contato: estudo da sociedade Paresi no contexto das relações interétnicas. 1985. Dissertação (Mestrado em Antropologia Social) - Museu Nacional, Universidade Federal do Rio de Janeiro, Rio de Janeiro, 1985.

MANZOLLILO, V. C. O. A cerca da dinamicidade Lexical. Soletras, A. I, n. 2, jul./dez, 2001. 
MCCLEARY, L. Sociolinguística. Texto Base do Curso de Letras/Libras na modalidade a distância. Florianópolis: UFSC, 2009.

OLIVEIRA, M. et alii. Os neologismos em línguas indígenas. Revista Socioleto, vol. 5, n. 13, 2014.

PEREIRA, E. S. Formação de palavras a composição na Língua Paresi (Aruák). Anais do Congresso de Línguas Indígenas de Mato Grosso, Faculdade intercultural indígena. Universidade do estado de Mato Grosso-UNEMAT, 2017.

ROWAN, O. Dicionário Paresi-Português. 2 ed. Cuiabá: Sociedade internacional de linguística, 2001.

SILVA, G. R. Morfossintaxe da Língua Paresi-Haliti (Aruák). 2013. Tese (Doutorado em Linguística) Faculdade de Letras, Universidade do Rio de Janeiro, 2013.

SILVA, G. R. Fonologia da lingua Paresi-Haliti (Aruák). Dissertação (Mestrado em Linguística) Faculdade de Letras, Universidade do Rio de Janeiro, 2009. 